\title{
DO ESTETICISMO BRASILEIRO: TRADIÇÃO E DEPENDÊNCIA
}

\author{
POR \\ FÁBIO LUCAS \\ Facultade Paulistana de Ciências e Letras
}

$\mathrm{Na}$ situação atual do Brasil, alguns escritores começam a conceber a língua não mais como um instrumento para representar uma realidade objetiva, cujo conteúdo se pretende apresentar e criar, não mais como um elo transparente entre a subjetividade e a objetividade; a linguagem literária começa a aparecer, ela tambén, como objeto portador de realidade própria. A revolução artística, portanto, não se limita apenas à mudança de ponto de vista em relação à sociedade, ao indivíduo, à natureza e às situações dramáticas da vida, mas também e necessariamente em relação à realidade que se cria com a expressão literária. Podemos mencionar, nessa linha de ficcionistas renovadores brasileiros, Guimarães Rosa, $\mathrm{Mu}$ rilo Rubião, Clarice Lispector e outros mais.

A valorização literária do texto, como tendência universal, coincide com uma propensão natural da psicologia brasileira, o esteticismo. Podemos desenvolver três argumentos para alcançar o significado do esteticismo brasileiro:

1) a nossa literatura teve início com o trabalho dos oradores, os homens do púlpito, que se exprimiam verbalmente pelos «sermões»e pelas «orações». $\mathrm{Na}$ ausência de imprensa e de pessoas letradas, procuravam persuadir, instruir, emocionar e deleitar pelo verbo que se dava em espetáculo. Daí o desenvolvimento da oratória pontilhada de sensacionalismo e de poder dramático, que acabou-se infiltrando na palavra escrita e, por fim, na Literatura. A ênfase catequética perdeu a sua funcionalidade com o tempo, mas permaneceu o resíduo estético do acento emocional por intermédio da expressão verbal;

2) a tradição barroca (cultista e conceptista) integrou-se como traço definitivo na psicologia coletiva brasileira, fazendo da forma irregular e 
do irrestrito formal um dos modelos da manifestação artística. É que o baixo teor racional e pragmático da sociedade, sempre em atraso com a revolução industrial e tecnológica do mundo, acolhe com simpatia a expansão formal incontida, não submetida aos cânones clássicos de acabamento da obra. Além do mais, a inconsciente indisciplina corresponde a um modo translato de fugir ao excessivo controle social exercido sobre: os estratos inferiores da sociedade;

3) as classes abastadas do país sempre desfrutaram de larga margem de ócio. Sendo as únicas letradas, fizeram do lazer um convite ao artesanato caprichoso e demoradamente elaborado. Cremos ser este um dos. aspectos que mais explicam a enorme potencialidade novelesca de nossa. criação. A complexidade temática, estrutural, sintática e vocabular ajustase maravilhosamente à índole brasileira. Daí o êxito extraordinário da. obra de Guimarães Rosa, um marco indiscutível na ficção brasileira de após-guerra. Desde a publicação de seu primeiro livro, um conjunto de contos (Sagarana, 1946), até a edição do último, em vida (Tutaméia, 1967), tornou-se um ponto de referência de nossa literatura, alvo de uma das mais copiosas bibliografias críticas do país e destinatário da censura azeda de alguns ficcionistas que não compreenderam o seu papel de liame entre as tendências universais e a modulação nacional daquelas tendências.

Com efeito, tendo o progresso e a difusão dos novos meios de comunicação levado a prosa de ficção a um mergulho na potencialidade exclusiva do campo literário, no que isso implica uma valorização estética da linguagem, tal característica contemporânea veio encontrar no Brasil um território favorável, considerada a nossa tradição.

Já se tem falado no «espírito barroco» do brasileiro, na sua psicologia de gestos inesperados e pouco afeito a uma programação rígida. A música popular e as atividades esportivas, pontilhadas de variações improvisadas, atestam esse caráter de ondulante variedade da psiquê nacional. Soma-se a isso o cunho ornamental de nossos trabalhos artísticos e mesmo o gosto monumental do artesanato popular.

Alguns autores insistem no esteticismo como especial modo de ser do homem brasileiro, do homem que contempla o mundo como um palco e a vida como um espetáculo. Trata-se, assim, de não deixar despercebido qualquer ato de nobreza ou qualquer gesto indigno, qualquer mérito, ação ou intenção louvável. Atos de solidariedade ou de vilania tendem a se tornar públicos e notórios. Assim, o brasileiro comum prefere a exteriorização dos sentimentos e admira pouco as qualidades humanas menos explícitas. $\mathrm{O}$ extremo bloqueio social, para assegurar a dominação de um 
grupo bastante minoritário da população, gera o sentimento de que qualquer concessão da clașse dirigente vem a ser uma dádiva, cuja atribuição deva ser exemplar, divulgada a todos os ventos.

No terreno da Literatura, é preciso notar a grande influência dos oradores sacros, especialmente o Pe. Antônio Vieira, de estilo barroco e rebuscado, que irá encontrar, no século Xxx, um fiel continuador em Rui Barbosa, tribuno de grande orquestração verbal e símbolo, na primeira República brasileira, da própia inteligência. Foi a mais completa representação da classe média pequeno-burguesa que, em determinada fase da evolução do Brasil, procura emergir em meio ao domínio da aristocracia rural. No período posterior à Segunda Grande Guerra, são conhecidos a enorme fortuna política de Carlos Lacerda, tribuno capaz de gerar crises nacionais simplesmente agitando bolhas de sabão, assim como a fulminante carreira de Jânio Quadros, apoiada na retórica do vazio. Todos são exemplos do ambiente propício para a expressão de largo efeito psicodinâmico, aristocrática, entusiástica e verbosa.

O estilo frondoso e enfático faz parte da tradição escrita brasileira (a que corresponde, dialeticamente, outra tradição de estilo ático, conciso): Euclides da Cunha, Coelho Neto, Raul Pompéia, José de Alencar, Castro Alves e, a seu modo, Monteiro Lobato e Oswald de Andrade constituem exemplos dignos de ser considerados. Cabe aqui uma referência especial a Cidade Calabouço (1973) de Rui Mourão, novela experimental em que, tomando como referente o "país do carnaval», cria uma atmosfera macabra e crítica, de junção de forças conscientes e inconscientes, instaurando um barroco espetáculo do «país do carnaval», isto é, o viver como realização teatral (note-se que $O$ País do Carnaval é o título do livro de estréia de Jorge Amado, publicado em 1931).

Nota-se, entre nós, a tendência de dar acento literário aos trabalhos científicos, principalmente aos de História (História encomiástica), Sociologia e Antropologia. Observem-se estas obras importantes da cultura brasileira: Um Estadista do Império de Joaquim Nabuco; Os Sertões de Euclides da Cunha; Populações Meridionais do Brasil de Oliveira Viana; Casa Grande \& Senzala de Gilberto Freire; Raízes do Brasil de Sérgio Buarque de Holanda. No dizer do crítico e sociólogo Antônio Cândido, a literatura tem sido no Brasil «mais do que a Filosofia e as Ciências Humanas, o fenômeno central da vida do espírito" (Literatura e Sociedade, São Paulo, 1966, p. 152). Daí as obras acima relacionadas serem frequentemente objeto de apreciação literária, ao lado de constituirem interpretação de diferentes períodos da sociedade brasileira.

O esteticismo, portanto, como inclinação natural do brasileiro, facultou o apuro literário das modernas produções na ficção e estimulou bas- 
tante o experimentalismo, vítima comumente do excessivo entusiasmo, da descontinuidade dos projetos e da improvisação. Fia-se demais na espontaneidade do gênio. No geral, as obras de caráter experimental são bem recebidas pela crítica literária. Domina alguns espíritos o pressuposto de que são boas e originais.

Restaria mais uma linha de consideração: o esteticismo, assim como o formalismo, poderiam constituir uma derivação da organização burocrática da sociedade instituída em Estado cartorial. Com efeito, o formalismo pode indicar a estrutura de poder que está por detrás das aparências mais notórias do rito comunitário.

Ancestralmente organizada para servir a úma camada estreita da população, a sociedade constituída torna o poder hermético, escondido por detrás de regrinhas casuísticas, de tal modo que a imensa maioria se vê despojada das condições elementares de atravessar o labirinto e de entender o sistema de dominação, no qual o comando se lhe afigura sempre fugidio. A burocracia é uma das faces que o formalismo assume para ocultar a posse do poder real. Escudo labiríntico.

A aparente beleza de nossas formas, deste modo, constituiria uma técnica de ofuscar a possibilidade crítica dos espoliados. A capacidade crítica se perde no esplendor dos ornamentos, entretem-se com o falso brilho, não podendo descer, via de regra, ao cerne da distribuição clara e equânime das tarefas sociais.

E curioso notar como o código civil brasileiro, de férreo perfil privatístico e senhorial, teve sua tramitação estacionada no Congresso durante mais de uma década por discussões de natureza gramatical. Deslocou-se para a purificação do idioma, normativamente compreendido quanto ao léxico e à sintaxe, o debate concernente às regras de convivência civil.

O lado formalista do nosso Direito tornou verdade apodítica a velha sentença que diz ser melhor um mau acordo que uma boa demanda. $\overline{\mathrm{E}}$ que a parte adjetiva do Direito, as regras de procedimento para se chegar à verdade, devoraram a parte substantiva. E, nas suas consequências práticas e sociais, dada a manipulação do aparelho judiciário e processualista, já se cunhou a síntese de nossa legislação assim: código civil para os ricos, código penal para os pobres (o dualismo entre ricos e pobres tem-se agravado através dos tempos, conforme comentaremos).

Deste modo, regidos por códigos de fino travejamento formal, temos sido dotados de uma legislação injusta, mas bem acabada. Inapreensível do ponto de vista adjetivo.

A ascensão de nova burocracia depois de 1964 e de um segmento da burguesia mais expansionista e concentracionário, orientados pelo princí- 
pio pragmático advindo da cultura protestante e anglo-saxônica — fruto da influência norte-americana em nosso destino nacional-, veio balançar a velha tradição das boas leis brasileiras, em que repousava o poder aristocrático e fundiário da sociedade rural. A pletora de novos mandamentos, rusticamente elaborados, mas eficazes para acelerar o sistema de poupança da economia e o crescimento industrial, emergiu como uma orgia de bárbaros. Mas, bem no fundo, permaneceu a mesma estrutura de classe e de poder, aperfeiçoada por uma violenta concentração de renda e um distanciamento maior entre pobres e ricos. O furor legisferante tornou reservado somente para iniciados o caminho da prática milagreira do desenvolvimento.

Dá-se, então, o renascimento do barroco, o ornamentalismo exagerado, a excitação social mediante festivais de música popular, carnaval turístico e disputas futebolísticas a nível nacional. A loteria esportiva criou a fantasia da ascensão social pelo acionamento das forças energéticas do acaso. Oficializou-se a exuberância do povo brasileiro, seu lado ufanista e triunfal. A «parte floral da genialidade», como diria Mário de Andrade. Mais uma vez, as formas de vibração e desequilíbrio convivem, em nossa História, com períodos de fechamento da sociedade.

Herbert Read identificou, certa vez, todo período clássico com o espírito repressivo. A seu ver, Classicismo é sinônimo de opressão. Somente os períodos barrocos ou românticos são capazes de desbloquear a mente prisioneira do encarceiramento social. Mas, na verdade, não há correspondência exata entre liberdades públicas e aceitação de formas barrocas.

No Brasil, por exemplo, o período barroco foi assinalado pelo aulicismo dos intelectuais, pela bajulação destemperada em que o poder autocrático se estrelava. Já o período clássico, dos Ârcades mineiros, motivou a literatura de resistência, de que as Cartas Chilenas são exemplo notório.

Quanto à funcionalidade do ornamento, Machado de Assis teve a percepção exata de seus efeitos na sociedade imperial brasileira. Usou de toda a sua capacidade satírica para desnudar a monumentalidade retórica, pondo a nu as mesquinharias subjacentes. Raymundo Faoro, na aguda investigação sociológica đa conduta literária do grande romanticista, pôs em destaque, em capítulo intitulado «Ideologia e retórica», o descompasso entre o caloroso debate doutrinário e intelectual que ocupava a elite dominante do período imperial, e a vulgaridade dos objetivos alvejados por aquela sociedade que se refinava em citações francesas e inglesas. «Era o idealismo que ocupava o lugar da ideologia. Este é o quadro do idealismo do Segundo Reinado, com suas fições sociais e psicológicas. Muito amor verbal aos princípios, louvores às cousas abstratas, que, traduzidas na realidade do dia, revelam-se incapazes de ação. A prática, 
desamparada de normas que com elas se ajustem, desagrega-se na intriga, nas nomeações e demissões, nos fornecimentos e eleições. Idealismo de colegial, que se compraz no jogo das idéias, jogo gratuito e frívolo» (Raymundo Faoro, Machado de Assis: a pirâmide e o trapézio, 2.a ed., São Paulo: Comp. Ed. Nacional, 1976, p. 169).

Machado, numa época triunfal do estilo frondoso; revelava-se cátustico para o palavrório oco. Entre as suas muitas personagens que manifestam paixão pela retórica e pelos recursos bombásticos, José Dias, de Dom Casmurro, ficou como uma das mais expressivas. O ponto convergente de sua expressão enfática residia no abuso dos superlativos, «um modo de dar feição monumental à idéias» (Dom Casmurro, cap. IV). Como a outras personagens da mesma índole, Machado de Assis endereça-lhe um comentário arrasador: "as cortesias que fizesse vinham antes do cálculo que da índole» (Dom Casmurro, cap. V).

Raymundo Faoro, depois de demonstrar ser a retórica um recurso lúdico de uma elite descompromissada com as bases, um debate de idéias travado nas nuvens, sintetiza com felicidade: «Inevitável, no quadro sem autenticidade das idéias e programas, a retórica em lugar do estudo das realidades, a teoria em lugar do conhecimento empírico, os chavões parlamentares em lugar do pensamento, da reflexão (R. Faoro, ob. cit., p. 166). No caso, um esteticismo falseador do real, tuma capa de enganos, uma ostentação da aparência para ocultar uma essência degradada.

O crítico e professor baiano David Salles trilhou um caminho paralelo no livro O Ficcionista Xavier Marques: um estudo da «transição» ornamental (Rio: Civ. Bras., 1977), ao situar o romancista analisado no contexto histórico nacional: «Ora, a vigência cultural do período em estudo concebia evolutivamente a Literatura como um aditivo ornamental, a conferir o polimento e transparência civilizada à cultura e à sociedade (...). Assim sendo, a Literatura, ela própria, evoluiu na direção da erudição superestrutural e do formalismo purista e mimético de padrões erigidos como civilizados» (David Salles, ob. cit., p. 42).

David Salles assinala inteligentemente que paradoxalmente, em seu europeísmo superficial, de imitação, para o elogio de torna-viagem, o projeto ornamental era provinciano em suas consequências» (David Salles, ob. cit., p. 43). O crítico analisa o valor meramente decorativo dos procedimentos retóricos de Xavier Marques.

Finalmente, uma observação a mais. Ao considerarmos a cultura brasileira, devemos ter em mente a profunda concentração de renda e da propriedade no país, que gera consequências fundamentais para a singularidade nacional. $\hat{E}$ que a tendência de se conservar uma sociedade estra- 
tificada a dois degraus constitui dois sistemas autônomos de circulação do saber: o erudito e o popular. Embora pareça esquemática a divisão, e se possa considerar uma instância intermediária (reservada, no séc. Xx, ao que se chamaria grosso modo a classe média urbana), é possível sustentar a dualidade, com pequeno risco de dispersão.

A sociedade baseada no poder das oligarquias irá projetar-se sutilmente na sociedade contemporânea de consumo de massa. A organização dual tende a tipificar-se como norma histórica e mecanismo promotor da capitalização desejada pela organização capitalista. Em outras palavras, o amadurecimento do capitalismo, ora ingressando no estádio financeiro como suporte da intensificação industrial, não implica uma rejeição da herança oligárquica. Antes projeção do velho e tradicional escalonamento social no quadro novo, consolidando-o e tornando-o mais adequado à formação de capital para o aceleramento da produção capitalista. Estamos na era dos oligopolios.

A sociedade de atividade agrícola, periférica e complementar do sistema capitalista central, passou do feitio escravocrata ao de mercado de trabalho, sem alterar o distanciamento entre os portadores de capital e os de força de trabalho.

A ascensão da classe média ao poder, celebrada por muitos autores como efetivada no movimento de 30 , não alterou, na verdade, a titularidade do poder. A novidade mais evidente foi a circulação mais rápida dos detentores eventuais da chefia, após a ditadura Vargas. De um ponto de vista externo, de puro registro de resultado, fica evidente um grau de instabilidade na designação dos donos ostensivos do poder: quedas bruscas, concessões, suicídio, renúncia, nomes contestados, golpes, contragolpes, tutela castrense, etc.

$\mathrm{Na}$ sociedade dual, de tão duradouro perfil, o formalismo da elite tem sido derivação quase que mercantil da nobreza intelectual dos centros hegemônicos. Vale o provérbio: a Europa se curva ante o Brasil. Também temos estilo alto, literatura refolhada de decoro, poesia de exportação. Enfim, a estética da dependência. Quanto à massa semiletra$\mathrm{da}$, que os meios de comunicação manipulam astuciosamente, extasia-se com o ópio da expansão barroca, o fervor nacional, o charme e a beleza de nossa gente.

A nosso ver, portanto, os dois sistemas de circulação do saber funcionam em aliança com o sistema superior de colonização. As elites intelectuais sentiram por muito tempo a vertigem da vanguarda (no campo da criação e no da crítica), entregando-se a um experimentalismo oco desprotegido de substancialidade, ou seja, de compromisso com as causas 
concretas da sociedade brasileira em seu esforço de superação do atraso cultural.

As classes populares, por sua vez, estão sendo manipuladas pelos meios de comunicação de massa, submetidas pela mística do consumismo e distraídas por operações desviacionistas. Deste modo, favoreceram-se as expansões acríticas (multidões entusiásticas do futebol e do carnaval), a paixão pelo jogo (existente, paralelamente, na concepção lúdica da estética elitista) e a crença na força do acaso (as variadas formas de loteria que encontram, nos grupos aristocráticos, correspondência no culto das obras do acaso, extraídas de máquinas, computadores e caixinhas de segredo, como poemas ocasionais, descartáveis).

Acentuou-se a carnavalização da prática nacional, o gosto dos grandes espetáculos, revivendo os áureos momentos do período barroco.

A revivescência do estilo barroco, a nosso ver, não passa de tentativa descabida de ilusionismo. A orquestação formal e a exuberância de expressão servem para ocultar a face íntima dos fenômenos e aplicam-se ao culto apologético da classe dominante. A miséria colorida, expansiva, entusiástica e falsamente alegre ajusta-se ao triunfalismo de um reduzido grupo que se vem perpetrando no poder, desde a organização do país nos seus primórdios.

Muitas crises políticas são provocadas para permitir alianças no setor hegemônico da sociedade e impedir que as contradições eventuais se resolvan em luta. Enquanto isso, as massas apartadas do poder são afagadas pelo formalismo vibrante e sensorial, com que se anestesiam as dores reais e se desviam as forças opositivas.

Na verdade, o barroco só tem sentido no seu quadro histórico e ideológico, quando se ligou ao desdobramento do. Renascimento e promoveu a continuidade do Maneirismo, sendo o esplendor deste e avatar do Academicismo e do estilo Rococó. O seu deslocamento para a era contemporânea traz consigo o propósito de conservar a função a que se destinou: a de permitir aos bacharéis, militares e clérigos letrados entregar-se à bajulação dos poderosos. A efusão entusiástica e as expansões inconscientes, que configuram o esteticismo contemporâneo, nada mais fazem do que diluir as energias na geléia conformista. Daí, não ser importante o elogio sistemático da capacidade de improvisação do nosso povo e de sua imensa e cordial paciência para com os ventos adversos. O esteticismo dual, elitista e popular, serve à mesma causa e orienta-se para o mesmo efeito: acentua a dependência, consolida os anéis ideológicos da dominação. A restauração dos esquemas tradicionais de ligações inter-subjetivas, o culto das virtudes passadas, o despertar e a orientação de energias ador- 
mecidas do povo nada mais são do que estratagemas da grande jogada colonial, que, no entanto, começou a sofrer os seus revezes. A tradição também pode ser utilizada num contexto crítico e, mesmo, revolucionário. A História nos está ensinando isso.

É preciso não esquecer que a nóssa literatura iniciou-se sob a regência do Barroco e que o nosso esteticismo tem servido aos mesmos senhores. Urge mudar o signo ideológico. 
